\title{
A System for Modelling of Processes for Data Accumulation and Synthesis in Higher Education
}

\author{
George Totkov, Silvia Gaftandzhieva, George Pashev, Stoyan Atanasov \\ University of Plovdiv “Paisii Hilendarski”, 24 Tzar Assen Str., Plovdiv, Bulgaria
}

\begin{abstract}
The paper presents a proprietary software system for Modelling of Processes for Data Accumulation and Synthesis in Higher Education, which is designed and developed to overcome the lack of tools suitable enough for work-flows manipulation in the field of Higher Education (HE). The system allows modelling processes in the form of "workflows", accumulation, aggregation and synthesis of information e-resources in relevant digital repositories, virtualization of processes, dynamic visualization of processes and/or their elements, integration and synchronization of heterogeneous software systems working with the system. A special focus is set on processes related to Quality Evaluation.
\end{abstract}

Keywords - Educational Process Modelling, workflows of activities, Automated Quality Evaluation, accreditation, University Digital Repositories, Automated Educational Systems

\section{Introduction}

The complexity of the task of designing and creating state-of-the-art information systems for management of processes is an argument in support of the idea of looking for solutions for the automation of activities and procedures in the respective subject area (SA). Few examples of such solutions can be found in the literature, especially in higher education (HE) [1].

DOI: 10.18421/TEM94-38

https://doi.org/10.18421/TEM94-38

Corresponding author: George Pashev, University of Plovdiv "Paisii Hilendarski". Email: georgepashev@uni-plovdiv.bg

Received: 29 July 2020.

Revised: 21 September 2020.

Accepted: 29 September 2020.

Published: 27 November 2020.

(c) BY-NC-ND (C) 2020 George Totkov at al; published by UIKTEN. This work is licensed under the Creative Commons Attribution-NonCommercial-NoDerivs 4.0 License.

The article is published with Open Access at www.temjournal.com
The quality system of the University of Graz, Austria [2] generates a huge amount of data for quality monitoring.

Information systems that collect statistics data play the central role in the system. A web application for monitoring of academic performance in real time, according to the Baldrige criteria was developed in Indonesia [3]. The application is based on the business intelligence technology and service-oriented architecture. It uses web services for integration, extraction and collection of data from different sources - academic system, LMS, student system, research system, public services system, etc.

On the other hand, successful full automation of business processes in a broader scope is unthinkable without experience in the development and use of information systems and digital repositories related to the relevant field on national and university level. We will especially mention the attempts for automated evaluation of the quality of the research in the Bulgarian Academy of Sciences, the rating of Bulgarian universities and virtualization of separate accreditation procedures of NEAA, as well as for the electronic registers of Bulgarian students and professors maintained by the Ministry of Education. There has also been some progress in the automated quality assessment (QA) of e-learning objects - from distance learning environments [1] to e-courses, digital activities and resources [4].

There are number of research studies of Business Process Management application in higher education domain, such as [5], [9], [10]. Some of them are performance management oriented, such as [6]. Some approaches like [7], [11], [12] in addition to performance management incorporate more complex strategies that allow personal level adaptivity to some extent by introducing management of personal targets. However, all of them fail to introduce enough formalized Business Process Model which would be suitable enough for HE applications and would take into account some problems we discuss in the next paragraph.

Despite the undoubted achievements in the field of automation of specific university spheres, many problems remain. These include: 
- the "manual" entry, processing and storage of big data sets, accompanied by their duplication and mismatch in university and national information systems;

- unsynchronized planning, decision making and control at different management levels;

- frequent changes in the regulatory framework (at national and institutional level);

- "on-site" practice for introducing specific rules for the document flow (with the argument and the idea of the need for "academic autonomy"), etc.

In our opinion, the possible solution to these problems requires the creation, testing and validation of tools for modelling, virtual implementation, visual representation and interface provisioning (including the integration of functionalities of heterogeneous information systems and big data) of business processes in various fields of HE. The general approach for automated quality evaluation, applicable to various software and implementation methodologies, presented in [1] provides not only the last statement but also a good basis for automation of business processes and other fields of study.

The paper presents a software prototype, based on process virtualization tools in higher education. Section 2 presents the essence of the approach suggested in [1]. Section 3 discusses a methodology based on a set of theoretical and software tools for the creation of "fast" software prototypes for automation of different fields of activity in HE.

\section{Digitalization of Evaluation and Accreditation Processes in HE in Bulgaria}

The increased workload, coupled with a reduction in the Agency staff (according to a decree of the Council of Ministers 11/ 03.02.2010), required the NEAA Accreditation Council (AC) to adopt a decision on the study of the automation of accreditation procedures. At its meeting of 3 June 2010, the AC heard, discussed and adopted a proposal for the creation of a prototype of an automated system at the University of Plovdiv "Paisii Hilendarski". As a result, a software system COMPASS (version 1.0) was designed and implemented.

In the period 2011-2014, COMPASS 1.0. was tested in accreditation procedures of the University of Plovdiv "Paisii Hilendarski" (institutional and professional fields), as well as to support the work of NEAA expert groups in the institutional accreditations of Sofia University "St. Kl. Ohridski" and South-West University "Neofit Rilski".

On the basis of the studies for automated extraction of data on the quality of HE objects and possibilities for automated extraction of data for NEAA criteria (programmes in distance learning, institution, professional fields and etc.), a software system COMPASS 2.0 was designed and tested [1]. A selfassessment report for the evaluation of the environment of distance learning at the University of Plovdiv (2015) has been prepared through COMPASS 2.0. Several appendixes to the report were generated automatically from data extracted from a learning management system.

Unlike COMPASS 1.0, the second version of the system has functionality for referencing various information objects in the self-assessment report (possibly not yet located in the university digital repository, but planned to be created in time) and their automated attachment as applications [1]. For this purpose, a common University Electronic Archive has been developed [4]. As a result, a nomenclature (taxonomy) of a university digital repository has been created, suitable for use by any Bulgarian university.

It should be noted that the system for automated management of internal document used by NEAA does not automate its main activities (similar to the situation with HEI's documents systems). Examples for such activities are conducting procedures and preparing accompanying reports, decisions and appendixes. The last statement is justified by the fact that the NEAA criteria systems, the rules and methodologies that follow the procedures for assessment and accreditation of HE are not modelled in the documents system of HE.

A similar conclusion can be drawn for many university information systems - they do not have the tools to model, modify, virtualize and support processes. A certain exception in this direction are information systems of the Thracian University (Stara Zagora) and the University of Plovdiv "Paisii Hilendarski".

\section{Modelling and Virtualization of Processes in $\mathrm{HE}$}

The approach used in COMPASS is universal - it can be used for quality evaluation of objects in HE using different NEAA criteria systems. The community of the approach lies in the possibility to model the elements of each quality evaluation system of criterion type in COMPASS (see [1] for more details).

To automate many business processes for a given subject area (not just the case of "HE assessment and accreditation procedures"), the following theoretical and software tools are needed:

A. Creating models of processes in HE, incl. related elements - sub-processes, rules and regulations; regulatory systems; subjects (management bodies, teachers, experts, administrators, etc.); 
information objects (HEIs, faculties, departments, professional fields and programmes, departments, etc.) and information resources (from normative, educational, research, administrative, reporting, information nature);

B. Formalize and set rules for the flow, interaction and synchronization of processes, with the formation and control (if necessary) of accompanying additional activities and solutions;

C. Starting, maintaining, completing and archiving of procedures specific to the modelled area of $\mathrm{HE}$;

D. Preparation of reports and analyzes of completed procedures, forthcoming activities, used (and/or required) resources, etc.;

E. Maintenance of specialized databases (DB) with remote access for the needs of the educational system (at national and institutional level).

It is desirable that tools of providing A - E to have the following characteristics:

- to automate core HE activities as much as possible;

- to provide flexibility (independence from any future changes to regulations, methodologies and procedures);

- optimize and avoid duplication of activities and data (especially when creating, storing and distributing documents);

- to provide dynamic management of modelled and virtualized processes;

- to reduce the time and resources spent in carrying out the ongoing procedures, etc.

To solve the problem of e-governance of HEspecific activities comprehensively, the idea realized in the COMPASS 2.0 system needs to be further developed by offering and realizing theoretical and applied (conceptual and computational) tools that allow adequate modelling, virtual conducting, visual presenting and providing of processes (including integrating the functionality of existing information systems and big data).

\section{A System for Virtualization of Processes in HE}

The basis and the possibility of implementing a system with the characteristics of the previous section are provided by COMPASS 2.0 and other Bulgarian development - EMSG (http://dextro-research.eu/) for modelling and managing the so-called "workflows" (workflow) [8]. The EMSG system has been successfully used for virtualization and support of healthcare and litigation processes. The design of the new software system COMPASS 3.0, can be seen as a next step in the development of COMPASS 2.0.

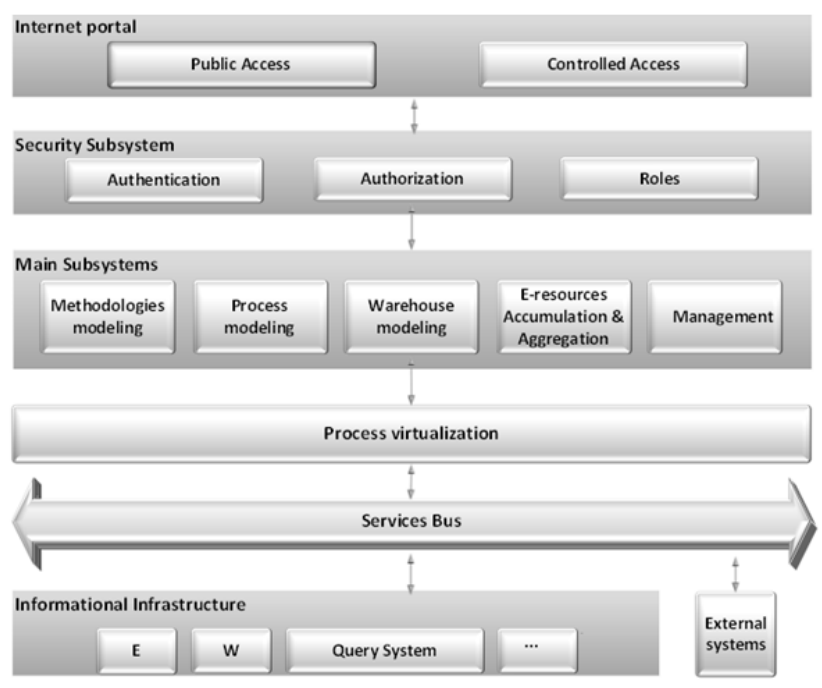

Figure 1. Architecture of a system for virtualization of processes in $\mathrm{HE}$

Analysis of objects, subjects and processes in HE shows that the architecture of the COMPASS 3.0 software system, designed for modelling, virtualization and dynamic management of workflows in corporative information infrastructure $\mathrm{E}$ with digital repositories W (Fig. 1.), should include subsystems for:

A. Modelling processes in the form of "workflows" [8];

B. Modelling of methodologies for dynamic visualization of processes and/or their elements (sub-processes, activities, subjects, objects);

C. Modelling of digital repositories in information infrastructures of different institutions;

D. Accumulation, aggregation and synthesis of information e-resources in relevant digital repositories (documents, reports, etc.) as a result of the implementation of virtualized processes;

E. Virtualization of processes (maintenance of their lifecycle) and/or their elements;

F. Communication and user interaction with COMPASS 3.0;

G. Management and synchronization of the work of COMPASS 3.0. and its subsystems.

Main features of COMPASS 3.0 must be:

- modelling processes in HE (in the form of workflows), visualization methods (suitable for presenting information resources/data), and digital repositories (for collective or personal use);

- dynamic management and control of access of the users to services (including for starting and maintaining virtual processes) and information resources;

- accumulation, aggregation and synthesis (including generation) of information resources depending on the relevant process; 
- management and control of the exchange of information resources - documents, reports, data, etc. (electronic document circulation) at different levels within the processes;

- automatic generation of standard documents and files (including letters, reports and decisions for initiating, conducting and finalizing processes and procedures);

- maintaining an electronic archive of documents, procedures and methodologies specific to $\mathrm{HE}$ activities (for upcoming, ongoing and completed procedures; for the discovery of information resources by various criteria, etc.);

- provision of public access to information on the status and results of HE processes, etc.

The fast software prototype of COMPASS 3.0 is developed on the basis of the integration of COMPASS 2.0 and EMSG components. Some experiments to automate specific activities in HE were planned and carried out. Among them are experiments for an automated assessment of the quality of research with the generation of data for the rating system, modelling and generation of optimal flows of activities and resources for conducting elearning [8], etc.

Fig. 2. presents a model of a process for quality evaluation of the research of a teacher, created with the COMPASS 3.0 prototype. Similarly, other representations of HE-specific processes can be created with the tools of COMPASS 3.0.

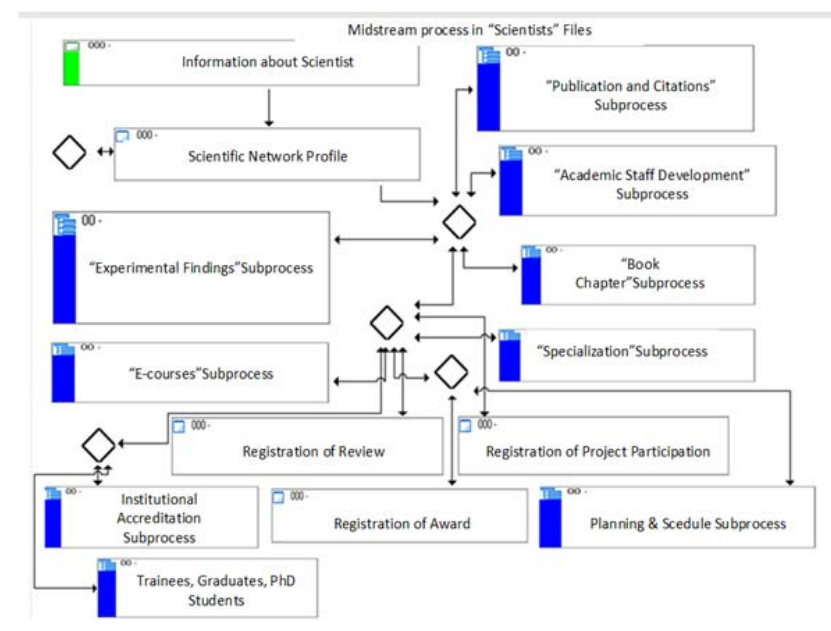

Figure 2. A model of a process for quality evaluation of research

The COMPASS 3.0 prototype caters for workflows that model real business processes. The models of complex business processes created through COMPASS 3.0 are presented (composed) as a set of relatively separate processes - each with its own life cycle (including startup, flow, completion) and rules for their interaction, synchronization and coexistence.

Each business process is modelled as a flow structure of activities (steps) in which can participate different information objects and subjects. The flow structure presents a flow chart of the process, i.e. models the interdependence and sequence of activities depending on time, logical and resource constraints.

The modelling of business processes is done using a graphical editor. Each startup of the process creates a specific instance of it in the system, which begins its own life cycle. The instance is marked as an event (step) in the procedure file.

The interface functionality of the system is created and visualized automatically for users, based on the process models presented in COMPASS 3.0.

Each process is defined by a set of parameters, among which the most important are the list of activities (steps) needed to complete the process and their schedule (in the form of a graph describing their sequence) and more. Each step can again be presented as a process - automatically or manually.

When manually entering data for a specific event, e.g. initiation ("entry") of a new business process, the respective user must consider - which process (from the models in COMPASS 3.0) the new event is associated with. For this purpose, to help the user, the system generates a list of processes - "potential" candidates, which could be attributed (depending on the logic of system models) to the new event. In the next step, the user will be able to select (tag) one or more processes in the generated list, creating eventprocess relationships.

COMPASS 3.0 also supports digital repositories of information resources for various purposes (see Fig. 3.).

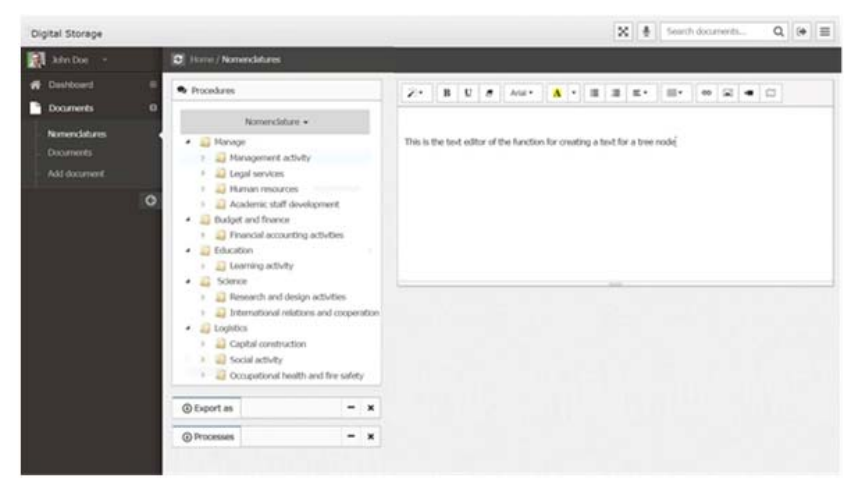

Figure 3. A model of university e-archive

In the case of virtualization of processes over university information infrastructure, the central role is played by the university digital archive. A model of an archive suitable for Bulgarian HEIs is proposed in [4]. With the help of COMPASS 3.0, the archive can be easily designed (Fig. 3.). Later, the archive can be built up with the accumulation of information resources - the result of virtualized processes, e.g. NEAA procedures related to the criteria systems for quality evaluation and accreditation (of institutions, programs, distance learning) and for capacity determination/change (Fig. 3.). 
In COMPASS 3.0, the following process categories are distinguished: Midstream, Standard and Subprocess.

The Midstream category includes processes for which there is only one instance (instance) at a time. An example of a process in the Midstream category is the procedure for accreditation of the HEI environment for distance learning. The procedure is unique (meaning - at any one time, there is one single copy of it) and standard - it includes the main steps:

- preparation of self-assessment (documentation) from the HEI, submission and acceptance (registration) of the package of documents at NEAA;

- starting the procedure;

- referral to a designated standing committee (SC), consideration by the $\mathrm{SC}$ (including the appointment of an observer and members of an expert group - EG, on-site visit, drafting of an EG report, adoption of a decision by the $\mathrm{SC}$, referral to the Accreditation Council - AC);

- issuance of a final act (by decision and recommendations of the $\mathrm{AU}$ );

- informing the HE of the decision;

- follow-up correspondence on the procedure (HE with answer/objections to $\mathrm{HE}$ );

- post-accreditation control, etc.

All NEAA procedures related to quality evaluation and HE accreditation can be modelled through processes in the Midstream category.

The Standard category includes (sub) processes that participate in the process descriptions of the Midstream category. In the example above (accreditation of a university environment for distance learning), a Standard type process is an "onsite visit by EG", a subprocess that is part of almost all other Midstream processes. This allows, after creating a model of such a sub-process, to be used repeatedly as an element of other processes without having to re-describe it.

At one time, it is possible to maintain multiple instances of Standard-type processes (for example, in the case of institutional accreditation, EG visits to different HEIs may take place at the same time).
The Subprocess category includes processes that are performed within processes in the Standard category (not in the Midstream category).

\section{A System for Virtualization of Processes in HE}

The COMPASS 3.0 software prototype is a convenient and effective tool for the automation of specific processes in HE, which is confirmed by the experiments performed and the universality of the theoretical model used.

It is necessary to carry out a larger-scale experiment, e.g. related to the automation of a separate group of NEAA activities to improve the presented approach. To ensure the experiment, it is necessary to discuss ways (such as typing and normalization) to increase the objectivity of the assessments and the precision of the recommendations (offered by the $\mathrm{AC}, \mathrm{SC}$ and NEAA Expert Groups) in the evaluation processes and accreditation. It should be remembered that in most cases, automation requires and is accompanied by a change of organization and enhancement of the efficiency and capabilities for dynamic management of the respective processes.

Particularly appropriate for the purpose of the experiment is the activity of the PC under the postaccreditation monitoring and control. First, the case processes are relatively the same type and generate typed (structured) documents. Second, for a relatively short period of time, all HEIs and SCs of NEAA are, in one way or another, involved in this procedure. Third, in a reduced form, a process involving subprocesses ("self-assessment", "evaluation", "acceptance of evaluations", "evaluation of evaluations", "pronouncement of evaluations", etc.) is carried out here, which are typical for other activities of NEAA. Fourth, the accompanying information resources (documents, reports, correspondence, etc.) are relatively small in number and can easily be located and organized in digital repositories. 


\section{References}

[1]. Gaftandzhieva, S. (2017). A Model and System for Dynamic Quality Evaluation in Higher Education (Doctoral dissertation, Doctoral dissertation, University of Plovdiv).

[2]. J. Haakstad et al. (2013) Audit of the University of Graz. Tampere: FINHEEC. Retrieved from: https://static.unigraz.at/fileadmin/portal/universitaet/Files/unigraz_Au dit 2013.pdf [accessed: 10 June 2020].

[3]. Wisnubhadra, I. (2013). Service Oriented Business Intelligence for Monitoring Academic Quality. In Proc. of the 2nd Intern. Conf. on DEI (pp. 136143).

[4]. Traykova, A. (2017). Optimizing hybridism: a critique of naturalist, normativist and phenomenological accounts of disease in the philosophy of medicine (Doctoral dissertation, Durham University).

[5]. Zhang, Y., Liang, R., Shi, Z., \& Ma, H. (2012). The Design and Implementation of a Process-Driven Higher Educational Administrative System. IERI Procedia, 2, 176-182.

[6]. Vuksic, V. B., \& Bach, M. P. (2014). Process Performance Management in Higher Education. International Journal of Engineering Business Management, 6.
[7]. Kahveci, T. C., \& Taşkın, H. (2013). Integrated enterprise management system for higher education institutions based on strategic and process management: The case study of Sakarya University. Procedia-Social and Behavioral Sciences, 106, 1505-1513.

[8]. G. Pashev (2017) Dinamichno Generirane I Optimalno Upravlenie $\mathrm{Na}$ Pototsi Ot DeǐNosti I Resursi Za Provezhdane $\mathrm{Na}$ Elektronnoto Obuchenie, PhD Thesis.

[9]. Bai, C., \& Sarkis, J. (2013). A grey-based DEMATEL model for evaluating business process management critical success factors. International Journal of Production Economics, 146(1), 281-292.

[10]. Kahloun, F., \& Ghannouchi, S. A. (2017, January). Defining the quality of business process modeling in higher education domain: Case of the process of tracking master's degree theses. In 2017 International Conference on Control, Automation and Diagnosis (ICCAD) (pp. 275-280). IEEE.

[11]. Birzniece, I., \& Kirikova, M. (2011). Interactive inductive learning: application in domain of education. Applied Computer Systems, 44(1), 57-64.

[12]. de Souza, P. L., do Prado, A. F., de Souza, W. L., Pereira, S. M. D. S. F., \& Pires, L. F. (2017, January). Combining Behaviour-Driven Development with Scrum for Software Development in the Education Domain. In ICEIS (2) (pp. 449-458). 